\title{
煤矿井田区地表沉陷对植被景观的影响 一以山西省晋城市东大煤矿为例
}

\section{全占军 ${ }^{12,3}$ 程 宏 $^{1,2}$ 于云江 ${ }^{3 *}$ 邹学勇 ${ }^{12}$}

（1 北京师范大学中国沙漠研究中心 北京 100875）（2 北京师范大学环境演变与自然灾害教育部重点实验室 北京 100875) (3 中国环境科学研究院, 北京 100022)

摘 要 借助地表沉陷预测模型, 预测了地表沉陷状况, 依据地表沉陷对景观的破坏程度划分出重度影响区和轻 度影响区; 在遥感及地理信息系统技术的支持下，把植被景观现状与地表沉陷影响区叠加，通过沉陷前后景观格局 的变化分析，对山西省晋城市东大煤矿的生态影响进行了探索性评价研究。结果表明:1) 重度影响区地表会出现 盆型、马鞍型和波浪型等塌陷或裂缝, 土壤侵蚀的作用将导致土壤养分空间格局发生明显变化。塌陷或裂缝周围 生境恶化, 成为养分流失源, 植被恢复困难; 养分汇处土壤水、肥条件优越, 植被演替迅速, 适当的人为干扰可以加 快区域生态环境的恢复步伐。2) 地表沉陷后 植被景观破碎及隔离程度严重, 原有的稳定态景观格局被打破, 随着 地形、土壤的空间变化 植被开始新一轮发展演替。由于原先占绝对优势的退化植被类型白羊草 (Bothriochloa ischemum)-百里香( Thymus mongolicus)型优势度下降, 同时, 大部分次优势景观的内部生态功能受影响不大, 这对景观整 体的生物多样性以及次优势景观类型的演替是有益的，但是，重度影响区对斑块的隔离呈直线性，这对物种迁移的 障碍是明显的。因此, 重视井田区的封育与引种工作, 科学规划、合理布局, 在此基础上, 引导植被演替沿着白羊草百里香型一白羊草-黄背草 (Themeda japonica) 型一灌木丛一阔叶林的方向发展是可行的。

关键词 地表沉陷 景观 最大斑块指数 景观形状指数 凝结度指数

\section{ASSESSMENT OF SUBSIDENCE IMPACT ON VEGETATION LANDSCAPE IN COAL MINING AREA - A CASE STUDY OF DONGDA MINE IN JINCHENG CITY , SHANXI PROVINCE}

\author{
QUAN Zhan-Jun ${ }^{1,23}$ CHENG Hong ${ }^{1,2}$ YU Yun-Jiang ${ }^{3 *}$ and ZOU Xue-Yong ${ }^{1,2}$ \\ (1 Center for China Desert Research , Beijing Normal University , Beijing 100875 , China)
}

(2 Key Laboratory of Environmental Change and Natural Disaster , Ministry of Education of China , Beijing Normal University , Beijing 100875 , China) (3 Chinese Academy of Environmental Sciences , Beijing 100022 , China)

\begin{abstract}
Ground subsidence and its effects on environment have been the core content of ecological and environmental assessment in coal mining area. Although there are researches on these topics, the results and methods show some uncertainties and few involves forecast analysis. This paper forecasts the status of ground subsidence using ground subsidence forecasting mathematical model and classifies the heavy or slight influencing areas based on the degree of destructions of landscape. Based on remote sensing (RS) and geographical information system (GIS), this paper overlays the existing state map of the vegetation landscape and the map of the influenced areas. The influence of mining on environment is analyzed by comparison of the landscape patterns before and after ground subsidence in Dongda Mine of Jincheng, Shanxi Province. The results showed that :1) in heavy influencing areas, there are some collapse or crack structure such as basin, saddle and wave etc. Soil erosion leads to obvious change in spatial distribution of soil nutrients. The environment near the collapse or crack areas worsens and becomes the source of nutrient loss. It is very difficult for the vegetation to recover in these areas. In nutrient-rich areas, the vegetation succession performs rapidly. Proper artificial disturbance can accelerate the recovery paces of the regional environment. 2) After the ground subsidence, the vegetation landscape is broken up and isolated severely. With the changes of landform and soil in space , the vegetation begins to perform a new round of succession. Because the degraded vegetation type , Bothrichloa is-
\end{abstract}


chaemum-Thymus mongolicus community, will decrease, and the internal ecological function of the sub-dominance landscape is not quite affected, it is helpful to biodiversity and sub-dominance landscape succession. However, there is a linear relationship between the isolation of heavy influencing areas and the resulting patches , the obstacle for species to move from one patch to another in heavy influencing areas is obvious. Therefore, we should place more emphases on environmental conservation in coal mining area. On this basis, it is feasible to guide vegetation succession along the direction of Bothrichloa ischaemum-Thymus mongolicus community Bothrichloa ischaemum-Themeda japonica community - bush - broad-leaved forest.

Key words Ground subsidence , RS , GIS , Landscape , Largest patch index , Landscape shape index , Patch cohesion index

我国煤炭资源储量丰富，目前已探明原煤储量 近 $1.5 \times \mathrm{P} \mathrm{kg}$, 我国又是世界产煤大国, 1989 年原煤 产量已突破 $10 \times 10^{11} \mathrm{~kg}$, 跃居世界第一位。煤炭资 源的广泛开发促进了国民经济的迅速发展，同时也 造成了严重的生态环境问题。截至 1997 年, 全国 1258 个县市开办各种煤矿 43 万处, 因煤炭开采塌 陷土地总计近 $30 \times 10^{4} \mathrm{hm}^{2}$, 并以每年 $2 \times 10^{4} \mathrm{hm}^{2}$ 的 速度继续增长(韦朝阳等, 1997)。地表塌陷破坏土 地资源和植物资源, 影响土地耕作和植被生长, 改变 地貌并引发景观生态的变化; 塌陷造成我国东部平 原矿区大面积土地积水受淹或盐渍化, 使西部矿区 水土流失和土地荒漠化加剧(范英宏等, 2003)。为 了保证国民经济的正常发展 预计到 2020 年煤炭仍 占一次性能源的 $70 \%$ 左右 (耿殿明和姜福兴, 2003 ）矿区生态环境问题将会更加突出。

科学地开展煤矿开采的生态环境影响评价非常 必要。我国对矿区生态环境的研究主要侧重两个方 面，一是对矿区生态环境破坏及发生源的系统评估; 二是研究寻找矿区生态环境保护和治理的技术措施 与管理对策。从已有的研究成果看, 多数集中在矿 区塌陷土地的复圼及生态恢复研究, 而对矿区生态 环境影响评价路线及方法的研究则相对较少 (耿殿 明等, 2001)。

地表沉陷及其对生态环境的影响预测评价是煤 矿开采项目生态环境影响评价的核心内容。目前应 用较多的是类比分析, 通过相似已建煤矿沉陷区的 调查分析, 预测即将建设项目区的发展趋势, 这些研 究基本能预测生态环境的发展方向,成为生态环境 影响评价的主要方法(马祥爱等，2004），但这种方 法表现出更多的经验性和不确定性, 缺乏过程的预 测分析, 且类比项目的相似性常常很难保证。因此, 地表沉陷的生态影响评价方法亟待丰富、创新。计 算机技术及数学模型的发展推动了地表沉陷预测的 发展, 基于地质条件、煤层赋存情况、煤层开采情况 以及地表移动变形监测的地表沉陷预测模型逐渐趋
于完善(隋枉华和陈奇，1995;赵扬锋等，2004)，因 此 煤矿开采后的地形地貌预测是可以实现的; 同 时遥感及地理信息系统在区域地表数据获取及空 间分析方面的优势也日渐突出, 这些都为基于景观 生态学的煤矿井田区生态环境影响预测评价提供了 发展的契机。本文首先借助地表沉陷预测模型, 预 测沉陷后地形地貌状况, 划分出地表沉陷对植被影 响的重度区和轻度区; 然后在遥感及地理信息系统 技术的支持下，把植被景观现状与沉陷影响区叠加， 通过沉陷前后格局的变化分析,对山西省晋城市东 大煤矿的生态环境影响做探索性研究，以期在这一 领域有新的突破。

\section{1 研究区概况}

东大煤矿井田位于 $112^{\circ} 21^{\prime} 34^{\prime \prime} \sim 112^{\circ} 31^{\prime} 04^{\prime \prime}$ E、 $35^{\circ} 40^{\prime} 32^{\prime \prime} \sim 35^{\circ} 49^{\prime} 49^{\prime \prime} \mathrm{N}$, 海拔在 $650 \sim 1080 \mathrm{~m}$,山区 面积占 $80 \%$,为典型黄土丘陵沟壑区。项目区属于 暖温带季风气候, 四季分明, 冬长夏短, 雨热同季, 季 风强盛。年平均气温 $10.3{ }^{\circ} \mathrm{C}$, 气温日较差明显, 一 般在 $11.1{ }^{\circ} \mathrm{C}$ 左右。年平均降雨为 $643.7 \mathrm{~mm}$, 其中 6 $\sim 8$ 月降水量约占 $55 \%$ 。区内土壤属褐土类, 4 个 亚类:山地褐土、粗骨性褐土、褐土性土和碳酸盐褐 土。

煤矿井田走向长 $11.0 \mathrm{~km}$,倾斜宽 $15.3 \mathrm{~km}$,面 积 $132 \mathrm{~km}^{2}$, 煤层埋深在 $600 \sim 850 \mathrm{~m}$, 平均采高 $5.2 \mathrm{~m}$ 。由于该区煤层深, 开采难度大, 因此项目区 周边并无开采历史 ,也没有地表沉陷发生。

\section{2 基础资料}

本次评价的数据源包括 :晋城市土地利用现状 图 (1:10 000)(2000 年出版)、晋城市林业资源图 (1: $50000)(2000$ 年出版)、晋城市土壤类型图 (1:50 000)（1990 年出版）、项目区地形图 (1:50 000) (1988 年出版)、2004 年 4 月 14 日 TM 遥感影像(项目区范 围内无云层覆盖)。 
同时, 通过 GPS 定位, 对项目区范围进行了现 场植被调查, 调查内容包括物种组成、植被盖度, 在 项目区内均匀布点, 取得植被调查记录 87 个, 用于 解译标志建立及解译结果验证。

\section{3 研究方法}

\section{1 植被景观类型划分}

在 GIS 软件的支持下，结合现场调查与已有资 料, 解译遥感影像 编制项目区景观类型图具体流程 (图 1)。

信息源: $25 \mathrm{~m}$ 分辦率TM影像，1:50000万各类专业图，文献资料 Information source: TM image of 25 meters resolution, all kinds

of professional pictures $(1: 50000)$, documents and materials

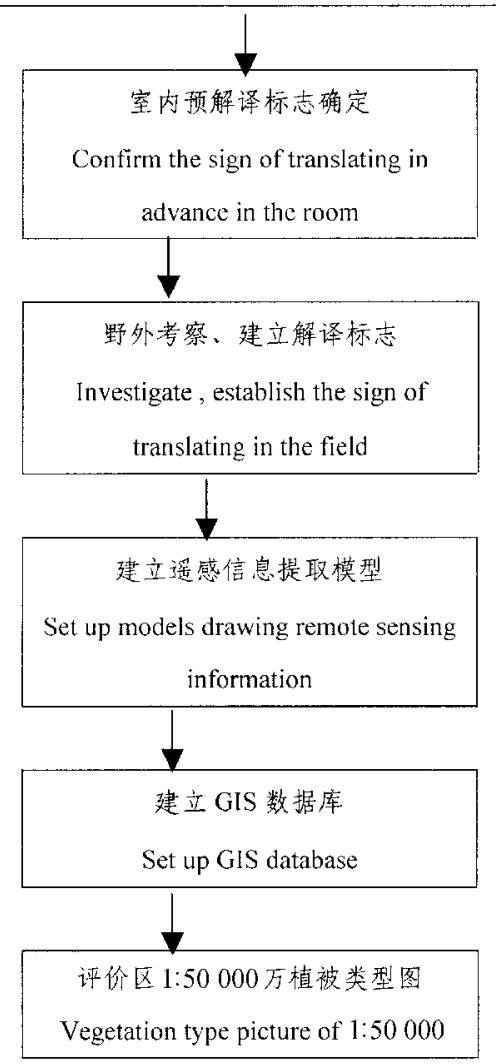

图 1 植被景观类型图获取流程

Fig.1 The technological process of vegetation landscape mapping

\section{2 地表沉陷等值线提取及影响等级划分}

根据晋城矿区多年开采实测资料,发现该地区 的地表沉陷符合概率积分模型，东大井田是晋城矿 区内规划的井田之一 其地质条件、煤层赋存情况以 及开采煤层与晋城煤业集团目前的生产矿井情况基 本相同。晋城煤业集团对现有生产矿井的地表移动 变形进行了大量监测, 积累了比较丰富的岩移观测 资料。因此本次地表沉陷预测参数的选取将根据晋
城矿区长期积累的实际观测经验参数，结合东大煤 矿的实际开采情况来确定。把确定的参数带入概率 积分模型，得到全井田区沉陷等值线图，如图 $2 \mathrm{a}$, 其 中最外侧等值线为 $-10 \mathrm{~mm}$, 最内侧等直线为 - $3500 \mathrm{~mm}$, 井田区内最大沉陷为 $-3700 \mathrm{~mm}$ 。东 大井田区属丘陵山地, 沉陷后不会发生地面积水, 主 要的地质问题就是采空区边缘的地表裂缝。本次研 究假设区域地质及岩土性质均一，即地表沉陷完全 依照预测的沉陷等值线发生。在地表沉陷预测结果 的基础上，我们做如下定义:采空区上方，基岩整体 下沉, 地形几乎无变化, 植被生境受破坏程度小, 定 义为轻度影响区 (i) 采空区边缘, 由于塌陷、裂缝和 滑坡等地质灾害频繁, 地表植被受破坏严重, 定义为 重度影响区(ii)。

\section{3 地表沉陷对植被景观影响分析}

首先, 叠加地表沉陷地质影响区域划分图和植 被景观图, 分别统计重度和轻度影响区内植被类型 面积, 分析植被破坏程度; 其次, 利用景观分析软件 Fragstats 3.3 计算区域内沉陷前后的景观最大斑块 指数、景观形状指数和斑块凝结指数, 通过对指标的 变化及诱因分析, 得到项目区生态环境影响评价结 果。本次评价所用的景观指数如下所示：

3.3.1 最大斑块指数 (Largest patch index, $L P I$ )

$$
L P I=\frac{\max \left(a_{i j}\right)}{A} \times 100
$$

式中 : $a_{i j}$ 是斑块 $i j$ 的面积; $A$ 是景观总面积。该指数 表示类型 $i$ 面积最大斑块占景观中的比例,简单表 达景观优势度, 指数越大, 优势越明显。

\subsection{2 景观形状指数 (Landscape shape index , LSI)}

$$
L S I=\frac{e_{i}}{\min \left(e_{i}\right)}
$$

式中 : $e_{i}$ 是景观中类型 $i$ 的总边缘长度 $\min \left(e_{i}\right)$ 为相 应类最大聚集程度下的最小边缘长度, 可以理解为 景观类型 $\mathrm{i}$ 在总面积一定的情况下, 聚集成一个简 单紧凑的景观斑块后其最小的边缘长度。该指数表 示景观空间的聚集程度, 也可以表示景观形状的复 杂程度。指数大, 表明景观空间分布离散, 景观形状 也不规则; 指数小, 则表明景观由几个简单大斑块聚 集而成。

3.3.3 斑块凝结指数 (Patch cohesion index, COHESION)

$$
\text { COHESION }=\left(1-\frac{\sum_{j=1}^{n} p_{i j}}{\sum_{j=1}^{n} p_{i j} \sqrt{a_{i j}}}\right) \times\left(1-\frac{1}{\sqrt{A}}\right)^{-1} \times 100
$$



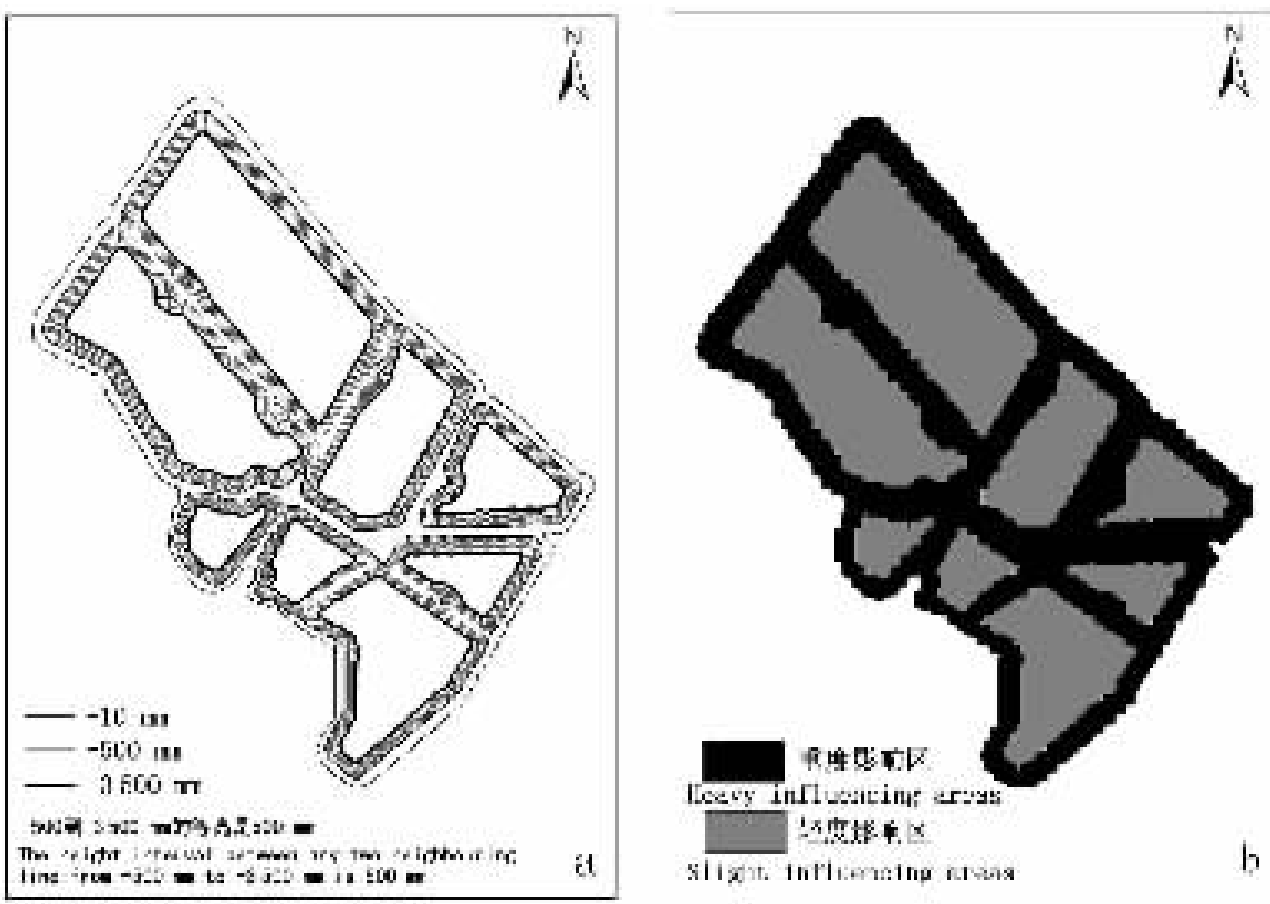

图 2 地表沉陷植被影响区域划分图

Fig.2 Division map of the effect of ground subsidence on vegetation

式中 : $a_{i j}$ 表示斑块 $i j$ 的面积 ; $p_{i j}$ 表示斑块 $i j$ 的周长 ; $A$ 表示景观总面积，用于测量类型 $i$ 的物理连通性。

\section{4 结果与分析}

\section{1 植被景观类型划分}

根据项目区特点及研究需要，综合林业资源图 和土地利用现状图, 将研究区植被划分为 8 个景观 类型 : 常绿针叶林 (I)、落叶阔叶林 (II)、灌木丛 (III)、 冬小麦( Triticum aestivum)农田系统 (IV)、玉米 (Zea mays)农田系统(V)、白羊草 (Bothrichloa ischaemum)黄背草 ( Themeda japonica) 型 (VI)、白羊草-百里香 ( Thymus mongolicus)型( VII) 和弃耕草丛 (VIII) , 景观 中各植被类型面积统计见表 1 。

按照功能差异将林地分为阔叶林、针叶林和灌 木丛。项目区位于黄土高原东部边缘地区，太行山 南麓。根据植被地带性规律, 项目区阔叶林属于落 叶型阔叶林, 主要有千斤榆 (Carpinus cordata)、葪栎 (Quercus aliena)、槲树 ( $Q$. dentata) 、辽东栋 $(Q$. liaotungensis) 和栓皮栋 ( $Q$. variabilis) 等。由于历史 的原因, 长期的人为破坏导致阔叶林生境逐渐退缩 到海拔较高的地区, 退化的阔叶林逐渐被以虎榛子 (Ostryopsis davidiana)、荆条(Vitex chinensis) 和胡枝子 (Lespedeza bicolor) 等灌木丛所取代, 针叶林主要以油 松( Pinus tabulaeformis)、华山松 ( P. armandii) 和侧
柏( Thuja orientalis) 为主。

研究区农作物属两年三熟耕作制度, 不同耕作 期农田表现出不同的生态功能, 因此将农田生态系 统分为冬小麦农田系统 (IV) ,玉米农田系统 (V) 两 类, 图像获取时 (2004 年 4 月 14 日)冬小麦已经进入 授粉期, 而玉米地还是留茬, 没有翻耕。

景观内斑块基质是两种草地生态系统, 分别为 白羊草-黄背草型和白羊草-百里香型。白羊草-百里 香型主要分布在土层薄, 土壤水分、养分条件差, 水 土流失严重的梁峁及阳坡, 覆盖度 $40 \%$ 左右, 产量 不高, 是一种退化严重的草场类型。以白羊草、百里 香为主, 还有少量的野艾蓄 (Artemisia lavandulaefoli$a$ )、兔丝子 (Cuscuta chinensis)、羽茅 (Achnatherun sibiricum) 和鬼针草 (Bidens bipinnata) 等。白羊草-黄 背草型主要分布在土壤较肥沃、水分条件较好的阴 坡和梁间地, 草丛高度达 50 100 cm , 群落繁茂, 生 产力较高。以白羊草、黄背草为主, 还有米口袋 (Amblytropis multifora)、刺叶柄棘豆 (Oxytropis aciphlla)、黄花藁 (Artemisia annua) 、䊁隐子草 (Cleistogenes squarrosa)、黄芩 ( Scutellaria tsinyunens)、石竹 (Dianthus chinensis)、委陵菜 (Potentilla chinensis)、达 乌里胡枝子 ( Lespedeza dahurica) 和柴胡 (Bupleurum chinense) 等以及少量的沙棘 (Hippophae rhamnoides)、 绣线菊 (Spirean thunbeigii) 和黄刺梅 (Rose Yanthin) 等 
灌木。另外由于国家退耕还林草实施以来, 弃耕地 逐渐演替为多年生草丛, 本研究单独划分为一种类 型。因此本研究对草地划分为白羊草-黄背草型 (VI) ,百羊草-百里香型 (VII) 以及杂草丛 (VIII) 3 种 类型。

\section{2 地表沉陷对植被景观的影响分析}

\subsection{1 地表沉陷对植被景观破坏分析}

煤层开采后, 采空区在上覆岩土层重力作用下, 发生变形弯曲, 冒落形成塌陷; 采空区边缘产生地表 裂缝, 使靠近塌陷区边缘的土地变为跑水、跑肥、跑 土”三跑田(司双印等 2004)。

由表 2 可知 地表沉陷影响植被景观总面积达 $80.39 \mathrm{~km}^{2}$, 其中轻度干扰 $58.38 \mathrm{~km}^{2}$, 重度干扰 22.01 $\mathrm{km}^{2}$ 。在重度干扰区 裂缝、塌陷活跃 植被景观破坏 严重, 应有的生态功能部分甚至完全丧失, 森林损失 $0.76 \mathrm{~km}^{2}$ 灌木丛损失 $3.29 \mathrm{~km}^{2}$ 耕地损失 $1.92 \mathrm{~km}^{2}$, 天然草地损失 $14.54 \mathrm{~km}^{2}$,弃耕草丛损失 $1.5 \mathrm{~km}^{2}$ 。 尤其是在耕地及草地景观内, 由于植物根系较浅, 地 表盖度低,往往演化为裸露的干土层,水土流失剧 烈植被恢复困难 轻度干扰区虽然地表也发生一系 列的沉陷变化, 但最终形式是整体的下沉, 植被破坏 程度相对较轻, 而且原有的景观类型不会发生改变。

4.2.2 地表沉陷的植被景观格局影响分析

从前面的分析可知 地表沉陷后, 重度影响区内
植被破坏严重, 应有的生态功能丧失, 演化为低盖度 植被甚至是干土层, 景观格局因此发生明显改变。

首先, 地表沉陷后景观破碎程度严重。由表 3 可知, 白羊草-百里香型受到最为严重的干扰, 沉陷 前白羊草-百里香型的最大斑块指数最大 (19.48), 沉陷后的最大斑块指数仅为 2.00 。其次是白羊草黄背草型, 沉陷前最大斑块指数 (1.05) 是沉陷后的 4.57 倍。阔叶林植被的最大斑块指数从沉陷前 (0.18)变化到沉陷后的 0.03 。农田生态系统受影响 同样严重, 冬小麦农田系统与玉米农田系统的最大 斑块指数由沉陷前的 0.42 与 0.55 变化为沉陷后的 0.14 与 0.30 ,说明景观内大面积农田基本被地表沉 陷所破坏、隔离, 大斑块耕地往往是优良高产田, 而 重度干扰区内地表裂缝及滑坡的出现, 势必加剧水 土流失，从而导致耕地产量下降。针叶林、灌木丛植 被和杂草丛由于本身现状中以小斑块为主, 破碎化 程度高, 因此受沉陷带切割影响较小, 最大斑块指数 变化不明显。

其次 地表沉陷裂缝或塌陷带给区域内斑块间 物种交流带来屏障。前面分析得出, 地表沉陷导致 景观破碎程度严重，依据景观形状指数的定义，该指 数值应该升高，从表 3 可知，所有植被景观类型的景 观形状指数不升反降。这是由于沉陷带的割裂, 使 得原来复杂的景观边缘被沿着直线方向割裂, 景观

表 1 植被类型面积统计表

Table 1 Statistics of vegetation type area

\begin{tabular}{lccccccccc}
\hline \multicolumn{1}{c}{ 类型 Type } & I & II & III & IV & V & VI & VII & VIII & 合计 Total \\
\hline 面积 Area $\left(\mathrm{km}^{2}\right)$ & 2.33 & 3.03 & 18.32 & 7.76 & 10.14 & 19.85 & 55.56 & 9.28 & 126.27 \\
面积比例 Percent of total $(\%)$ & 1.75 & 2.30 & 13.78 & 5.76 & 7.63 & 15.00 & 41.79 & 6.98 & 94.97 \\
\hline
\end{tabular}

I 常绿针叶林 Evergreen conifer forest II 落叶阔叶林 Broad-leaved forest III 灌木丛 Bush IV 终小麦农田系统 Winter wheat V :玉米农田系 统 Maize VI :白羊草-黄背草型 Bothrichloa ischaemum-Themeda japonica community VII :百羊草-百里香型 Bothrichloa ischaemum-Thymus mongolicus community VIII : 弃耕草丛 Abandoned land 无植被区域和水域共 $6.69 \mathrm{~km}^{2}$,占景观的 $5.03 \%$ The area of non-vegetation and water are $6.69 \mathrm{~km}^{2}$,which is $5.03 \%$ of total area

表 2 地表沉陷对植被景观影响面积统计

Table 2 Statistic of the effect of ground subsidence on vegetation type

\begin{tabular}{|c|c|c|c|c|}
\hline \multirow[t]{2}{*}{ 类型 Type } & \multicolumn{2}{|c|}{$\begin{array}{c}\text { 轻度干扰区 } \\
\text { Slight influencing areas }\end{array}$} & \multicolumn{2}{|c|}{$\begin{array}{c}\text { 重度干扰区 } \\
\text { Heavy influencing areas }\end{array}$} \\
\hline & 面积 Area $\left(\mathrm{km}^{2}\right)$ & 比例 Percent of total (\%) & 面积 Area $\left(\mathrm{km}^{2}\right)$ & 比例 Percent of total (\%) \\
\hline I & 1.59 & 2.72 & 0.35 & 1.61 \\
\hline II & 1.93 & 3.30 & 0.41 & 1.88 \\
\hline III & 11.06 & 18.94 & 3.29 & 14.94 \\
\hline IV & 2.21 & 3.79 & 0.78 & 3.56 \\
\hline V & 2.60 & 4.45 & 1.14 & 5.16 \\
\hline VI & 9.42 & 16.13 & 3.35 & 15.21 \\
\hline VII & 26.51 & 45.41 & 11.19 & 50.83 \\
\hline VIII & 3.08 & 5.27 & 1.50 & 6.81 \\
\hline 合计 Total & 58.38 & 100.00 & 22.01 & 100.00 \\
\hline
\end{tabular}


表 3 地表沉陷前后景观格局指数对比

Table 3 The comparison with landscape pattern index before and after ground subsidence

\begin{tabular}{|c|c|c|c|c|}
\hline & $\begin{array}{l}\text { 类型 } \\
\text { Type }\end{array}$ & $\begin{array}{c}\text { 最大斑块指数 } \\
\text { Largest patch index }\end{array}$ & $\begin{array}{c}\text { 景观形状指数 } \\
\text { Landscape shape index }\end{array}$ & $\begin{array}{c}\text { 斑块凝结指数 } \\
\text { Patch cohesion index }\end{array}$ \\
\hline 沉陷前 & I & 0.03 & 8.90 & 93.80 \\
\hline \multirow[t]{7}{*}{ Before ground subsidence } & II & 0.18 & 11.06 & 96.45 \\
\hline & III & 0.25 & 23.91 & 97.20 \\
\hline & IV & 0.42 & 34.12 & 97.14 \\
\hline & $\mathrm{V}$ & 0.55 & 34.21 & 96.58 \\
\hline & VI & 1.05 & 45.68 & 98.39 \\
\hline & VII & 19.48 & 32.10 & 99.88 \\
\hline & VIII & 0.03 & 22.52 & 92.42 \\
\hline 沉陷后 & I & 0.02 & 5.29 & 91.00 \\
\hline \multirow[t]{7}{*}{ After ground subsidence } & II & 0.03 & 7.47 & 94.52 \\
\hline & III & 0.19 & 15.77 & 96.55 \\
\hline & IV & 0.14 & 20.04 & 94.17 \\
\hline & $\mathrm{V}$ & 0.3 & 19.26 & 89.86 \\
\hline & VI & 0.23 & 31.02 & 97.09 \\
\hline & VII & 2.00 & 23.40 & 99.22 \\
\hline & VIII & 0.03 & 10.83 & 92.10 \\
\hline
\end{tabular}

I VIII :同表 1 See Table 1

虽然破碎了, 但形状变的简单了, 物种在斑块间迁移 变得更加困难。

最后 虽然景观破碎化程度严重, 但大部分植被 景观的内部稳定性变化不大。通过对斑块凝结度指 数的分析可知, 由于地表沉陷的发生, 景观连通性都 不同程度的降低,降低最多的是玉米农业系统,由 96.58 降至 89.86 ,表明景观内部功能受到严重影 响 ;其它类型降低不多，尤其是白羊草-百里香型，从 99.88 降到 99.22 , 说明虽然这些类型相对优势度下 降,但其内部的稳定性变化不大。

\subsection{3 地表沉陷的植被景观过程影响预测}

由于地表沉陷所带来的景观格局的改变打乱了 现有生态系统的平衡，必将引起新一轮的植被演替。 两种森林生态系统由于系统本身抗干扰能力强, 地 表沉陷对其景观过程的影响不是很明显，两种农田 植被系统由于是人工生态系统, 人为因素更强, 会适 时针对地表沉陷做出农业调整措施。植被演替最活 跃的应该是两种草地景观 (白羊草-百里香型和白羊 草-黄背草型) 和灌木丛景观。沉陷后由于土壤侵蚀 加剧，土壤养分空间格局分布变化明显。养分源处 生境恶化, 使之有利于白羊草-百里香型蔓延; 养分 汇处土壤条件优越, 使之有利于白羊草-黄背草型蔓 延。同时沉陷带内灌木丛植被受割裂程度小, 因此 灌木丛植被将向白羊草-黄背草型入侵。综上所述, 白羊草-黄背草型作为白羊草-百里香型与灌木丛之 间的过渡带, 是消失率最大的一种景观类型。另外， 轻度影响区景观虽然没有受到微地形干扰影响, 植 被演替也不会很剧烈, 但裂缝带的出现切断它与外
界的物质能量流通道, 因此轻度影响区景观影响是 间接的,但是意义深远。

\section{5 结论与讨论}

\section{1 结论}

1)重度影响区地表会出现盆型、马鞍型和波浪 型等塌陷或裂缝，土壤侵蚀的作用将导致土壤养分 空间格局发生明显变化。塌陷或裂缝周围生境恶 化, 成为养分流失源, 植被恢复困难, 必须借助水土 保持工程及生物措施; 养分汇处土壤水、肥条件优 越 植被演替迅速，适当的人为干扰 (引种、封育) 可 以加快区域生态环境的恢复步伐。

2)地表沉陷后, 植被景观破碎及隔离程度严重， 原有的以白羊草-百里香型为基质的大集中小分散 的稳定态景观格局被打破，随着地形、土壤的空间变 化 植被开始新一轮发展演替。由于原先占绝对优 势的退化植被类型白羊草-百里香型优势度下降, 同 时, 大部分次优势景观的内部生态功能受影响不大, 这对景观整体的生物多样性以及次优势景观类型的 演替是有益的，但是，沉陷带对斑块的隔离呈直线 性，这对物种迁移的障碍是明显的。因此，重视井田 区的封育与引种工作，科学规划，合理布局，在此基 础上,引导植被演替沿着白羊草-百里香型一白羊草 -黄背草型一灌木丛一阔叶林的方向发展是可行的。

\section{2 讨论}

首先，本次研究假设地表沉陷完全依照预测沉 陷等值线发生, 但由于复杂的山区地形与黄土区土 壤的特殊性质, 地表在移动变形过程中经常伴有附 
加其上的滑移地表移动和变形的分布特征与地形、 地貌也有较大的关系(毛汉英和方创琳，1998); 同 时，区域地质及岩土性质存在空间异质性，因此地表 沉陷不会完全依照沉陷等值线发生，如何表征实际 情况的地表沉陷需要进一步讨论。

其次, 在景观预测分析过程中需考虑地表沉陷 对地下水的影响 地表沉陷破坏地下岩体结构, 各含 水层间形成水体通路 (施群德等，2000) ;由于土壤 结构的变化地下潜水位都将改变 (梁明和王成绪, 2001) 地表沉陷对土壤-植被连续体的研究将需要 多学科的共同努力。

最后, 景观研究中必须考虑尺度问题 ( Lu et $a l$. ,2003) 地表沉陷景观影响分析过程中不仅关注 空间尺度, 更应特别关注时间尺度。地形变化、土壤 形成与植被演替在时间尺度上不在一个数量级 (Huggett，1991) 地形变化与土壤演化间断而缓慢， 植被演化则相对迅速。尽管 Jonathan 已提出了 4 个 概念的理论模型, 可以解决其中的一些问题, 但需要 进一步开发更实用的转换工具。地貌演化机制一直 是地形学界关注的热点问题 (Phillips, 1995) ,当前有 关矿产资源开采对地貌的影响研究主要是基于地形 学角度而进行的, 更多关注地形演化、土壤冲刷及沉 积过程( Whitney，2002)，还没见到有关它对景观过 程影响的研究, 开展矿产资源开采对景观过程影响 的研究可以借助于景观动态与模型预测已经取得很 多令人鼓舞的研究成果, 将有助于促进煤矿开采地 表沉陷景观影响评价。

\section{参 考 文 献}

Fan YH(范英宏), Lu ZH(陆兆华), Cheng JL(程建龙), Zhou ZX (周忠轩), Wu G (吴钢) (2003). Major ecological and environmental problems and the ecological reconstruction technologies of the coal mining areas in China. Acta Ecologica Sinica (生态学 报),23,2144-2152. (in Chinese with English abstract)

Geng DM(耿殿明), Jiang FX(姜福兴) (2003). Analysis on ecological environment of mine area in China. Coal Mine Environmental Protection(煤矿环境保护), 16(6), 5-10. (in Chinese)

Geng DM(耿殿明), Jiang FX (姜福兴), Zhang PZ (张朋柱) (2001). Some theoretical difficulties about sustainable development of coal mines. China Mining Magazine (中国矿业), 10 (5), 18 - 21. (in Chinese with English abstract)

Huggett RJ(1991). Climate, Earth Processes, and Earth History.
Springer, Berlin, 281 .

Liang M(梁明), Wang CX(王成绪) (2001). Prediction of mining subsidence in mountain area overlaid with thick loess bed. Coal Geology and Exploration (煤田地质与勘探), 29(2), 44 - 47 . (in Chinese with English abstract)

Lu L, Li X, Cheng GD(2003). Landscape evolution in the middle Heihe River Basin of north-west China during the last decade. Journal of Arid Environments, 53, 395 - 408 .

Ma XA(马祥爱), Bai ZK(白中科), Shao YH(邵月红), Zhang $\mathrm{SH}$ (张世海), Wu JS(吴俊松), Zhao M(赵民) (2004). Ecoenvironmental impact assessment on subsidence with coal mining in Loess Hilly Areas_-Taking Kaiyuan Mine of Yangquan Coal Limited Company as example. Journal of Shanxi Agriculture University (山西农业大学学报), 24, 47 - 52. (in Chinese with English abstract)

Mao HY (毛汉英), Fang CL(方创琳) (1998). Cave-in land types by coal mining and their comprehensive utilization ecological model. Acta Ecologica Sinica (生态学报), 18,449 - 455.（in Chinese with English abstract)

Phillips JD (1995) . Biogeomorphology and landscape evolution: the problem of scale. Geomorphology, 13,337-347.

Shi QD(施群德), Zhao JF (赵建锋), Su ZJ (苏仲杰) (2000). Prospects and developments of study on fractals in mining subsidence. Journal of Engineering Geology (工程地质学报) , 8, 341 - 344. (in Chinese with English abstract)

Si SY(司双印), Zhang YB(张运备), Ma JJ(马敬杰), He LL (贺留兰), Qin SC(秦世昌) (2004). Restoring the eco-environment and sustainable economic development in collapse area of coal mines. Journal of Geological Hazards and Enironment Preservation (地质灾害与环境保护) , 15(3), 11-16. (in Chinese with English abstract)

Sui WH(隋枉华), Chen Q(陈奇) (1995). Simple comment on research meaning, present situation, mechanism of soil mass settlement deformation caused by coal bed mining and the way of forecast. The Chinese Journal of Geological Hazard and Control (中国地质灾害与防治学报),6(1),1-6. (in Chinese with English abstract)

Wei CY(韦朝阳), Zhang LC(张立城), He SJ(何书金) (1997).

A discussion on the eco-environmental conditions in the coal mining areas in China. Acta Geographica Sinica (地理学报), 52, $300-307$. (in Chinese with English abstract)

Whitney JA (2002) . Landscape evolution of the five islands of south Louisiana: scientific policy and salt dome utilization and management. Geomorphology, 47,227-244.

Zhao YF (赵扬锋), Zhang HX (张华兴), Pan YS (潘一山) (2004). Numerical simulation of overlay stratums' effect to subsidence of stripe mining. Coal Mining Technology (煤矿开采), 9 (3), $1-3$. (in Chinese with English abstract) 